Special issue of the 3rd International Conference on Computational and Experimental Science and Engineering (ICCESEN 2016)

\title{
Usability of Fuzzy Logic Modeling for Prediction of Fresh Properties of Self-Compacting Concrete
}

\author{
A. BeycioĞLU ${ }^{a, *}$, A. GÜltekin ${ }^{b}$ And H.Y. Aruntaş ${ }^{c}$ \\ ${ }^{a}$ Düzce University, Civil Engineering Department, Düzce, Turkey, \\ ${ }^{b}$ Ege University, Civil Engineering Department, İzmir, Turkey \\ ${ }^{c}$ Gazi University, Civil Engineering Department, Ankara, Turkey
}

\begin{abstract}
The aim of this study is to investigate the usability of fuzzy logic modelling for prediction of fresh properties of self-compacting concrete. In the modelling process, the percentage of fly ash and the percentage of granulated blast furnace slag, as replacement of cement, the percentage of micronized calcite, as replacement of total aggregate, were used as inputs. The slump flow diameter and time and also the V-funnel time were used as outputs. Results show that fuzzy logic modelling may be a useful approach to predict fresh properties of self-compacting concrete, containing fly ash, granulated blast furnace slag and micronized calcite.
\end{abstract}

DOI: 10.12693/APhysPolA.132.1140

PACS/topics: 07.05.Mh, 28.52.Fa

\section{Introduction}

Concrete is one of the most widely used construction materials. Concrete engineers work continuously to improve the technological properties of the concretes. Nowadays, interdisciplinary studies on concretes have become more and more popular. Joint studies of physicists and civil engineers, to develop concrete for radiation shielding applications, can be given as a very important and specific example [1-3]. As a result of the studies performed by civil engineers, many special concrete types have emerged. One of the most popular special concrete types is the self-compacting concrete (SCC). Self-compacting concrete has little resistance to flow, and thus, it can be placed and compacted under its own weight, with no vibration effort [4].

Industrial byproducts, such as fly ash, slag, and granulated blast furnace slag, are being used as supplementary cementing materials, to reduce the environmental pollution. Besides, industrial byproduct materials are important for reducing the cost of SCC $[4,5]$.

Nowadays, artificial intelligence methods are much more popular in engineering sciences $[6,7]$. Fuzzy logic (FL) concept, an artificial intelligence method, was introduced by Zadeh [8]. FL modelling provides good solutions for controlling of the ambiguous, time-varying, complex and ill-defined systems, encountered in the daily life [9].

Recently, fuzzy logic has been extensively used in the fields of civil engineering applications and there are many studies available in the literature, in which different properties of concrete are modeled using fuzzy logic $[10,11]$.

In this study, it was aimed to investigate the usability of FL modeling for prediction of fresh properties of SCCs.

*corresponding author; e-mail: abeycioglu@duzce.edu.tr

\section{Fuzzy logic modeling, details and findings}

Mamdani-type FL models were developed for prediction of fresh properties of SCCs, containing fly ash (FA) and granulated blast furnace slag (GBFS), as replacement of cement, and micronized calcite (MC), as replacement of total aggregate.

Experimentally obtained results (results of the study are given in Ref. 4) of fresh state properties of SCCs were used to develop FL models. The fresh state properties of SCCs, used as output parameters for developing the models in this study, were slump flow diameter (SFD), slump flow time to spreading to $500 \mathrm{~mm}$ diameter (T500) and V-funnel flow time (VFT).

Two models were developed in MATLAB FL toolbox. One of the models was developed using GBFS (20\%, 40\% and $60 \%)$ and $\mathrm{MC}(5 \%$ and $10 \%)$ as inputs, while the other model was developed by using FA $(20 \%, 40 \%$ and $60 \%)$ and $\mathrm{MC}(5 \%$ and $10 \%)$ as inputs. General structures of the models are given in Fig. 1.

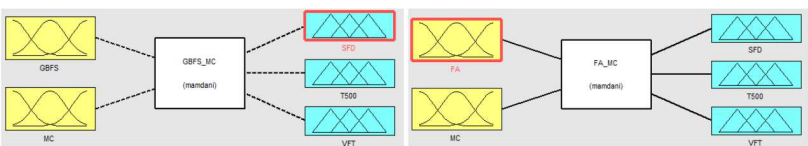

Fig. 1. General structure of the developed FL models.

Fresh state parameters of SCCs, as functions of inputs, according to the rules, formed in the developed FL models, are given in Fig. 2.

To obtain crisp output values (fresh state properties) of the models, defuzzification was performed by centroid of area method. As the last step of the modelling process, crisp results of the model were obtained from the defuzzification interface of FL toolbox. Findings of experimental and FL models are given in Tables I and II. 


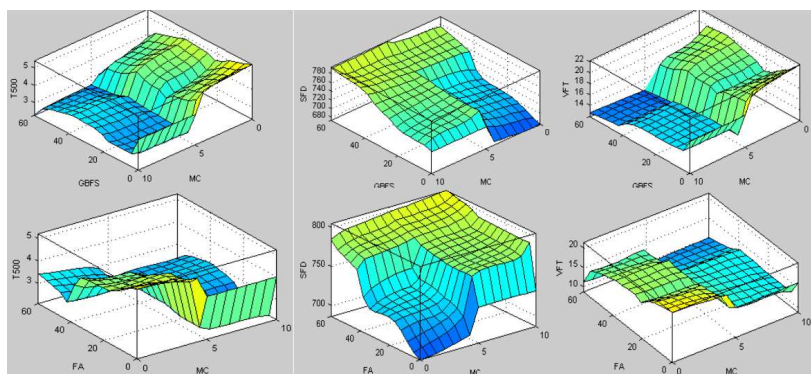

Fig. 2. SFD, T500 and VFT parameters of SCCs as functions of GBFS, FA and MC.

TABLE I

Experimental and FL modeling results of SCCs containing GBFS and MC.

\begin{tabular}{c|c|c|c|c|c|c|c}
\hline \hline \multicolumn{3}{l|}{ Input parameters } & \multicolumn{5}{|c}{ Experimental and FL modeling results } \\
\hline GBFS & MC & SFD & SFD-FL & T500 & T500-FL & VFT & VFT-FL \\
\hline 0 & 0 & 653 & 675 & 5.95 & 5.45 & 24 & 22.3 \\
20 & 0 & 719 & 702 & 4.40 & 4.24 & 17.6 & 16.9 \\
20 & 5 & 747 & 752 & 2.96 & 2.82 & 13.6 & 13.5 \\
20 & 10 & 735 & 732 & 2.98 & 3.01 & 14.33 & 15.2 \\
40 & 0 & 743 & 742 & 4.40 & 4.91 & 18,9 & 20.2 \\
40 & 5 & 767 & 762 & 3.10 & 3.09 & 13.3 & 13.1 \\
40 & 10 & 787 & 784 & 3.20 & 3.42 & 13.6 & 13.7 \\
60 & 0 & 773 & 776 & 3.96 & 3.85 & 13.3 & 13.4 \\
60 & 5 & 798 & 797 & 2.52 & 2.55 & 11.74 & 12.1 \\
60 & 10 & 793 & 793 & 2.18 & 2.28 & 12.85 & 12.6 \\
\hline & & $R^{2}=0.9531$ & $R^{2}=0.9467$ & $R^{2}=0.9557$ \\
\end{tabular}

TABLE II

Experimental and FL modeling results of SCCs containing FA and MC.

\begin{tabular}{c|c|c|c|c|c|c|c}
\hline \hline \multicolumn{2}{l|}{ Input parameters } & \multicolumn{5}{|c}{ Experimental and FL modeling results } \\
\hline FA & MC & SFD & SFD-FL & T500 & T500-FL & VFT & VFT-FL \\
\hline 0 & 0 & 653 & 686 & 5.95 & 5.22 & 24 & 21.4 \\
20 & 0 & 753 & 721 & 3.80 & 4.42 & 14.28 & 14.3 \\
20 & 5 & 765 & 767 & 2.50 & 2.48 & 14.6 & 15 \\
20 & 10 & 788 & 789 & 2.06 & 2.11 & 12.65 & 12.6 \\
40 & 0 & 757 & 758 & 2.30 & 2.32 & 16 & 18.2 \\
40 & 5 & 780 & 777 & 2.50 & 2.67 & 14 & 13.9 \\
40 & 10 & 793 & 792 & 3.00 & 3 & 13.41 & 13.4 \\
60 & 0 & 787 & 785 & 3.50 & 3.43 & 11.75 & 11.2 \\
60 & 5 & 794 & 799 & 2.43 & 2.41 & 8.54 & 8.72 \\
60 & 10 & 811 & 806 & 2.24 & 2.2 & 9.23 & 9.84 \\
\hline & & $R^{2}=0.8838$ & $R^{2}=0.9283$ & $R^{2}=0.9301$ \\
& & \multicolumn{6}{|c|c|}{}
\end{tabular}

\section{Conclusions}

In this paper, two FL models were developed by using FL Toolbox in MATLAB. Fresh state properties of SCCs containing GBFS, FA and MC were predicted by these models. When the values of the coefficient of determination $R^{2}$ are evaluated, it can be concluded that FL modeling may be used to predict the fresh state properties of SCCs, such as slump flow diameter, slump flow time to spread of $500 \mathrm{~mm}$ in diameter and V-funnel flow time.

\section{References}

[1] Ş. Kılınçarslan, B. Akyol, Acta Phys. Pol. A 130, 441 (2016).

[2] İ. Akkurt, K. Günoğlu, C. Başyiğit, Ş. Kılınçarslan, A. Akkaş, Acta Phys. Pol. A 123, 341 (2013).

[3] İ. Akkurt, C. Başyiğit, A. Akkaş, Ş. Kılınçarslan, B. Mavi, K. Günoğlu, Acta Phys. Pol. A 121, 138 (2012).

[4] A. Beycioğlu, H.Y. Aruntaş, Construct. Build. Mater. 73, 626 (2014).

[5] V. Fugaru, S. Bercea, C. Postolache, S. Manea, A. Moanta, I. Petre, M. Gheorghe, Acta Phys. Pol. A 127, 1427 (2015).

[6] C. Başyiğit, İ. Akkurt, Ş. Kılınçarslan, A. Beycioğlu, Neural Comput. Applicat. 19, 507 (2010).

[7] A. Beycioğlu, M. Emiroğlu, S. Subaşı, Y. Koçak, Comput. Concrete 15, 89 (2015).

[8] L.A. Zadeh, Informat. Control 8, 338 (1965).

[9] U.N. Baykan, M. Erdal, L.O. Ugur, Romanian J. Mater. 47, 54 (2017).

[10] A. Beycioğlu, C. Başyiğit, Acta Phys. Pol. A 128, B-424 (2015).

[11] İ. Akkurt, C. Başyiğit, Ş. Kılınçarslan, A. Beycioğlu, J. Franklin Instit. 347, 1589 (2010). 